Egyptian Journal of Rabbit Science, 25(2): 185 - 196(2015)

\title{
PREDICTION OF TOTAL MUSCLE WEIGHT FROM MORPHOMETRIC LIVE TRAITS IN RABBITS USING PRINCIPAL COMPONENT ANALYSIS
}

\author{
G.F. Gouda; A.R. Shemeis and O.Y. Abdallah \\ Animal Production Department, Faculty of Agriculture, Ain Shams University, \\ Shoubra El-Kheima, 11241 Cairo, Egypt
}

A total number of two hundred and eighteen New Zealand White rabbits were used to predict total muscle weight using nine live body measurements taken on the head, chest, loin, round and total body length and their three principle component varimax rotated scores. Total muscle weight (TMW) was more variable than any morphological live trait.

The highest phenotypic correlations with total muscle weight were recorded with the live measurements of the most meat-producing regions in the body ( $r=0.77,0.75,0.76,0.60$ and 0.58 for chest width, loin width, chest girth and abdomen girth, respectively). Results showed that out of the principal components (PCs) calculated, the first three explained $74.14 \%$ of the total variance. The PC1, PC2 and PC3 explained, respectively, 29.33, 23.23 and $21.58 \%$ of the generalized variance. Based on correlations of: (i) 0.913, 0.919, 0.582 and 0.594, PC1 is primarily a measure of width of chest and loin and girth and depth of chest, (ii) 0.705, 0.778 and 0.864, PC2 is primarily a measure of girth of chest, abdomen and round, (iii) 0.776, 0.791 and 0.696, PC3 is a measure of width of head and length of head and body. The stepwise involvement of PC1, PC2 and $P C 3$ in regressions predicting TMW were as follows: $T M W=728.3+$ 100.8 PC1 $\left(R^{2}=51 \%\right), T M W=728.3+100.8 P C 1+59.3 P C 2\left(R^{2}=\right.$ $69 \%)$ and $T M W=728.3+100.8 P C 1+59.3 P C 2+48.2 P C 3\left(R^{2}=\right.$ $80 \%)$.

Conclusively, Apply of principal component analysis was beneficial for avoiding any possible multicolinearity to occur and, thus, excluding any erroneous decisions to be taken when morphological body measurements were put together in a multiple regression.

Key words: Principal component analysis, body measurements, total muscle weight, rabbits. 
Linear body measurements have been used as predictors to estimate some carcass attributes in rabbits (Ogah, 2011; Oliveira et al., 2004; Pinna et al., 2004; Shemeis and Abdallah, 2000; Lukefahr and Ozemba, 1991). However, the great number of predictors together with the existing multicollinearity among them when put together in multiple regression model would lead to wrong decisions.

Principal component analysis (PCA) is known (Constantin, 2014) to reduce the number of variables under analysis to small number of factors and to break the possible multicollinearity among them. So far, there is dearth of information on the interrelations among carcass muscle weight and morphometric traits of rabbits using a multivariate approach. Several researchers have employed independent variable scores derived from PCA to predict other carcass attributes and some live body traits (Akinsola et al., 2014; Egena et al., 2014; Udeh, 2013; Ajayi and Oseni, 2012; Shahin, 2001; Shahin and Hassan, 2000).

The relationships involving total muscle weight and morphological traits may be different when orthogonal conformation traits derived from principal component factor analysis are used instead of the intercorrelated body linear variables.

Therefore, the present study was aimed at providing estimates of total muscle weight in New Zealand White rabbits using principal components.

\section{MATERIALS AND METHODS}

\section{Source of data:}

A total number of two hundred and eighteen New Zealand White rabbis were chosen randomly at their 12-week marketing age. They were born and reared at the "Private Qanater Rabbit Farm", Qalyobia governorate.

\section{Management of animals:}

At the 28-day weaning age, rabbits were separated from their dams and kept in fattening batteries where they were fed ad libitum, until marketing, a commercial pelleted diet containing $18.8 \%$ crude protein, $11.0 \%$ crude fiber and $2.4 \%$ crude fat and providing $2800 \mathrm{kcal}$ digestible energy $/ \mathrm{kg}$ diet.

\section{Traits considered}

At marketing, the following measurements were taken on the carcass after slaughtering: 
(i) On the carcass: total muscle weight (TMW), which was obtained by doubling the dissected side muscle weight from the carcasses held at $2^{\circ} \mathrm{C}$ for 24 hours after dressing the rabbits at the Ain Shams University, Faculty of Agriculture Meat Laboratory. While, the following live body measurements (LBM) were recorded before slaughtering:

(ii) On the head:

- Head width (HW) measured as the distance between the two eyes and

- Head length (HL) is the distance from in-between the ears to the tip of nose.

(iii) On the chest, loin and abdomen:

- Chest width (CW) measured along the transverse diameter of the thorax, the greatest - width of chest just behind the shoulders,

- Loin width (LW) measured along the transverse process of lumber vertebrae just in - front of the hind legs,

- Chest girth (CG) measured surrounding of the thoracic cavity just behind the fore legs,

- Abdominal girth (AG) measured surrounding the abdomen at the middle distance between the fore legs and hind legs and

- Chest depth (CD) is the dorsal-ventral distance between the most dorsal point of the withers and the ventral surface of the sternum.

(iv) On the round:

- Round girth (RG) measured surrounding the thigh at its maximum perimeter.

(v) On the total body:

- Body length (BL) measured from the first thoracic vertebrae to the last sacral vertebrae along the dorsal mid-line.

\section{Statistical analysis}

SPSS (2007) statistical package program was applied for simple statistics calculation and the principal component analysis.

Means, standard deviations and coefficient of variations of TMW and LBM were calculated and the Pearson's correlation coefficients (r) between TMW and LBM were estimated. Data for the PCA were generated from the correlation matrix. Anti-image correlations, Kaiser-Meyer-Olkin (measures of sampling adequacy) and Bartlett's test (test the null hypothesis that the original correlation matrix is an identity matrix) were computed to test the validity of the factor analysis of the data sets. TMW was predicted from linear 
body measurements and from principal component factor scores with varimax rotation by using the following stepwise multiple regression models:

$\mathrm{TMW}=\mathrm{a}+\mathrm{B}_{\mathrm{i}} \mathrm{X}_{\mathrm{i}}+\ldots \ldots \ldots \ldots . . . \mathrm{B}_{\mathrm{k}} \mathrm{X}_{\mathrm{k}} \ldots \ldots \ldots \ldots \ldots$ (1)

TMW $=a+B_{i} P_{i}+\ldots \ldots \ldots \ldots+B_{K} P_{K}+\ldots \ldots \ldots \ldots$ (2)

Where:

TMW $=$ The total muscle weight, $\mathrm{a}=$ The regression intercept and $\mathrm{B}_{\mathrm{i}}=$ the $i^{\text {th }}$ partial regression coefficient of the $i^{\text {th }}$ linear body measurements $\left(\mathrm{X}_{\mathrm{i}}\right)$ or the $\mathrm{i}^{\text {th }}$ principal component $\left(\mathrm{PC}_{\mathrm{i}}\right)$.

\section{RESULTS AND DISCUSSION}

\section{Phenotypic variations:}

Descriptive statistics of total muscle weight and live morphological traits are presented in Table 1 . Total muscle weight appeared more variable than any live morphological trait. Its variation in the present study was comparable to that obtained by Shahin (2001) (C.V.= 19.4 vs $23.5 \%$, respectively). The head which is known to be the earliest maturing region in the animal body showed the least variation for its bony measurements (C.V. = 4.9 and $4.7 \%$ for HW and HL, respectively). The chest, loin and round which are known to have intermediate maturing rate, presented average variation for their measurements $(C . V .=16.5,13.9$ and $13.3 \%$ for $\mathrm{LW}, \mathrm{CW}$ and $\mathrm{RG}$, respectively).

\section{Coefficients of phenotypic correlation:}

Pearson's coefficients of phenotypic correlation among various linear body measurements and total muscle weight are given in Table 2 , with stronger correlations (above 0.5) are shown in boldface. The highest correlation with TMW was recorded for TMW with CW $(\mathrm{r}=0.77, \mathrm{P}<0.01)$ and for TMW with $\mathrm{LW}(\mathrm{r}=0.75, \mathrm{P}<0.01)$ on one hand, and for TMW with CG $(\mathrm{r}=0.76, \mathrm{P}<0.01)$, TMW with AG $(\mathrm{r}=0.60, \mathrm{P}<0.01)$ and TMW with $\mathrm{CD}(\mathrm{r}=$ $0.58, \mathrm{P}<0.01)$, on the other. This suggests that body measurements of width, girth and depth of the trunk region are the most correlated with TMW. In agreement with these results, Shemeis (1999), on the same breed of rabbits, reported that using abdominal girth would be more efficient than using round girth to predicting meatiness. 
Table 1. Descriptive statistics of the body measurements $(\mathrm{cm})$ and total muscle weight (gm)

\begin{tabular}{l|c|ccc}
\hline \multicolumn{2}{c|}{ Measurements taken on the: } & Mean & SE & CV\% \\
\hline (i) Total carcass & TMW & 728.2 & 9.50 & 19.4 \\
(ii) Head & HW & 4.1 & 0.01 & 4.9 \\
& HL & 9.2 & 0.03 & 4.7 \\
(iii) Chest, loin and abdomen & CW & 5.1 & 0.04 & 13.9 \\
& LW & 5.5 & 0.06 & 16.5 \\
& CG & 23.4 & 0.11 & 7.1 \\
& AG & 26.3 & 0.13 & 7.3 \\
(iv) Round & CD & 5.9 & 0.03 & 8.5 \\
(v) Total body & RG & 18.4 & 0.14 & 13.3 \\
\hline
\end{tabular}

TMW: Total muscle weight, HW: Head width, HL: Head length, CW: Chest width, LW: Loin width, CG: Chest girth, AG: Abdomen girth, CD: Chest depth, RG: Round girth, BL: Body length.

Lower correlations (though significant) were obtained in this study, as compared to those given by Shahin and Hassan (2000) on the same breed, between body length and chest width $(r=0.21$, Table 2 and $r=0.75$, Shahin and Hassan, 2000) and between body length and round girth $(r=0.40$, Table 2 and $r=0.71$, Shahin and Hassan, 2000). The higher correlation between chest girth and abdomen girth in the present study $(\mathrm{r}=0.78)$ was comparable to that previously obtained $(\mathrm{r}=0.80)$ by Gouda and Shemeis (2014) on the same breed.

In agreement with the present study, Lewczuk et. al. (2001) on Danish White rabbits indicated the chest conference to be among the predictors of the highest correlation with carcass lean weight.

Correlation estimates reported in the present work between total muscle weight and chest girth $(\mathrm{r}=0.76)$ and between total muscle weight and chest width $(r=0.77)$ were comparable to those previously given by Michalik et. al. (2006) on French Lop rabbits for the relationship between carcass meat and chest girth $(\mathrm{r}=0.61)$ and between carcass meat and chest width $(\mathrm{r}=0.63)$. 


\section{Principle components:}

A total number of nine principle components (Figure 1) have been calculated, out of which three fulfilled the conditions of usage of PCA (i.e. each component being represented by more than one variable; eigenvalues are greater than one; the components taken together explain high percentage of total variance).

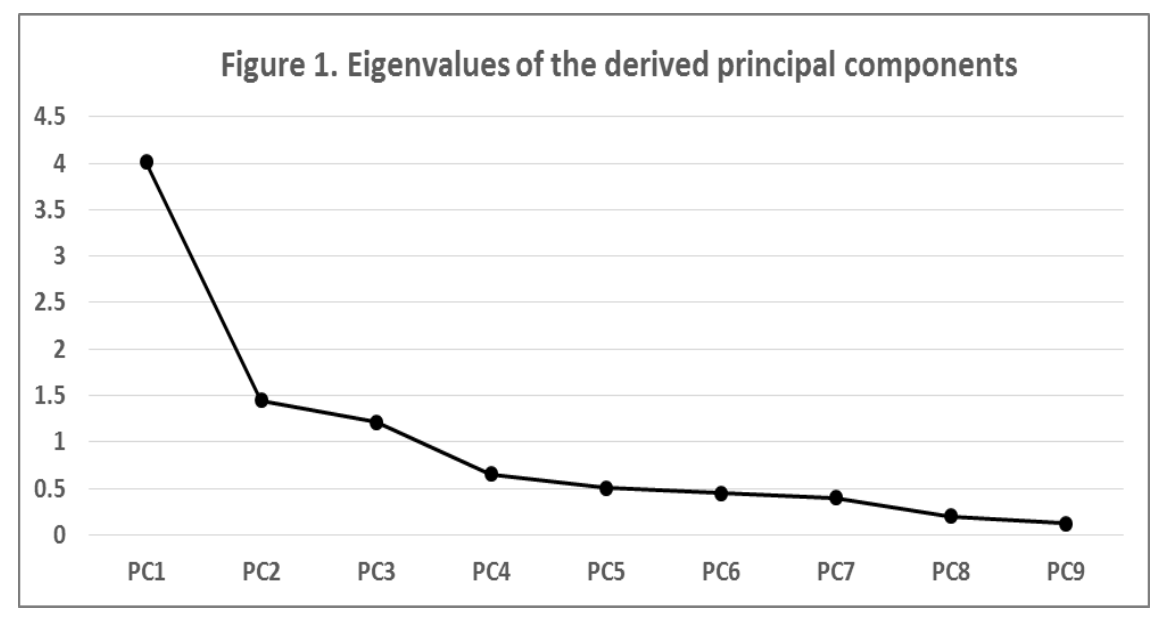

After varimax rotation of the component matrix, three factors were extracted. To interpret each component, the correlations between the original data for each variable and each principal component were computed (Table 3). Interpretation of the principal components is based on finding which variables are most strongly correlated with each component. The larger correlations are in boldface in Table 3 .

The first principal component (PC1) is strongly correlated with four of the original variables. The PC1 increases with chest width, loin width, chest girth and chest depth. This suggests that these four criteria of the trunk region vary together, if one increases the remaining criteria increase. Based on the correlation of 0.913 and 0.919 , the PC1 is primarily a measure of width of chest and loin. It would follow that rabbits with high chest girth and chest depth would tend to have great width at chest and loin. Such measures of width would reflect the development of muscle longissimus thoracis et lumborum the weight of which is traditionally used to predict total carcass muscle weight. 
Table 3. Correlations between original body measurements and principal component factors

\begin{tabular}{l|c|cccc}
\hline \multicolumn{2}{c|}{ Measurements taken on the: } & PC1 & PC2 & PC3 & Communality \\
\hline (ii) Head & HW & 0.177 & 0.063 & 0.776 & 0.64 \\
(iii) Chest, loin and & HL & 0.241 & 0.029 & 0.791 & 0.69 \\
Abdomen & CW & 0.913 & 0.088 & 0.162 & 0.87 \\
& LW & 0.919 & 0.059 & 0.132 & 0.87 \\
& CG & 0.582 & 0.705 & 0.165 & 0.86 \\
& AG & 0.404 & 0.778 & 0.053 & 0.77 \\
(iv) Round & CD & 0.594 & 0.182 & 0.362 & 0.52 \\
(v) Total body & RG & -0.129 & 0.846 & 0.154 & 0.76 \\
\hline Eigenvalues & BL & 0.033 & 0.473 & 0.696 & 0.64 \\
\hline
\end{tabular}

The second principal component (PC2) can be viewed as a measure of how great the rabbit body circumference is in terms of the girth at the level of chest (0.705), abdomen (0.778) and round (0.846).

The third principal component (PC3) is highly correlated with body length, head length and head width. This suggests that rabbits with high body length also tend to have larger head size. The PC1, PC2 and PC3 explained, respectively, 29.33, 23.23 and $21.58 \%$ of the generalized variance.

Estimation of total muscle weight from interdependent live body measurements and their independent principal component scores:

The results of stepwise multiple regression to predict TMW were given in Table 4, using the original linear body measurements (analysis i) and the principal component factors of linear body measurements (the orthogonal traits, analysis ii).

In analysis i, chest width explained most of the total variation in TMW $\left(\mathrm{R}^{2}=60 \%\right)$. Addition of chest girth to the model increased the accuracy of total muscle weight prediction by $13 \%$. Chest width and chest girth were already referred to (Table 2) as the most correlated variables to TMW. Addition of head length (HL) to the model involving CW and CG increased the accuracy of prediction by 4\%. Stepwise addition of further original traits did not increase accuracy of prediction of TMW by no more than $4 \%$. Thus, a practical three-linear- measurement regression equation for estimating TMW is: $\mathrm{TMW}(\mathrm{gm})=-1176.6+65.1 \mathrm{CW}+87.0 \mathrm{CG}+36.6 \mathrm{HL}\left(\mathrm{R}^{2}=77 \%\right)$. 
Table 4. Stepwise multiple regression of total muscle weight on original linear body measurements and on their principal component factors

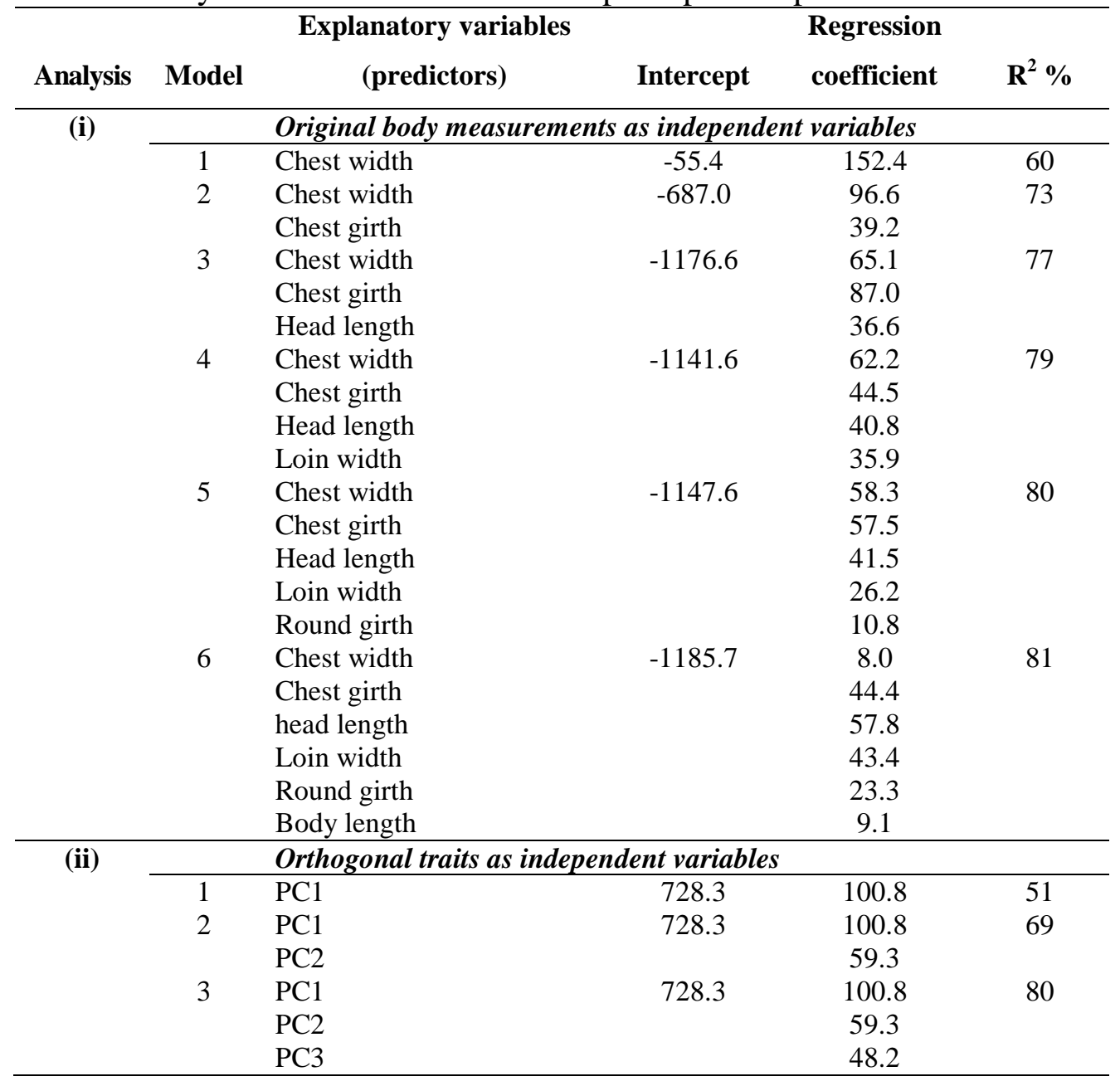

The justification of usage of PCA appeared clearly from the results given in Table 4 whenever two predictors (CW and CG) are used, an accuracy of $73 \%$ are obtainable. The accuracy reached $79 \%$ through use of four predictors (CW, CG, HL and LW), three out of which presented high degree of multicollinearity (the variance inflation factor, vif, for CW, CG and LW were, respectively, 4.36, 4.27 and $3.83 \%$ ).

In analysis ii, PC1 alone contributed to $51 \%$ of the total variation in TMW. Addition of PC2 to the model increased the accuracy of TMW 
prediction by $18 \%$. The increase in such accuracy as a result of adding PC 3 to the model was limited to $11 \%$. Thus, a reliable three-factor-score regression equation for estimating TMW is: TMW $(\mathrm{gm})=728.3+100.8 \mathrm{PC} 1+59.3 \mathrm{PC} 2$ +48.2 PC3 $\left(\mathrm{R}^{2}=0.80\right)$. This prediction equation is a reasonable alternative to the 4-original-measurement equation, as the 3-principal component equation gives almost the same accuracy without any degree of multicollinearity (vif=1.00).

Conclusively, apply of principal component analysis was beneficial for avoiding any possible multicolinearity to occur and, thus, excluding any erroneous decisions to be taken when morphological body measurements were put together in a multiple regression.

\section{REFERENCES}

Ajayi B.O., Oseni S.O. 2012. Morphological characterisation and principal component analysis of body dimensions in nigerian population of adult rabbits. Proceedings $10^{\text {th }}$ World Rabbit Congress, 3-6 September. Sharm El-Sheikh, Egypt. pp: 229-233.

Akinsola O.M., Nwagu B.I., Orunmuyi M., Iyeghe-Erakpotobor G.T., Eze E.D., Abanikannda O.T.F., Onaadepo O., Okuda E.U., Louis U. 2014. Prediction of bodyweight from body measurements in rabbits using principal component analysis. Annals of Biological Sciences, 2 (1):1-6.

Constantin, C. 2014. Principal component analysis-a powerful tool in computing marketing information. Bulletin of the Transilvania University of Braşov. Series V: Economic Sciences, 7 (56), No. 2.

Egena S.S.A., Akpa G. N., Aremu A., Alemede I. C. 2014. Sources of shared variability in body weight and linear body measurement traits of two breeds of rabbit. International Journal of Plant, Animal and Environmental Sciences, 4 (2): 141-145.

Gouda, G.F. and Shemeis, A.R. 2014. Prediction of body fatness from body measurements in New Zealand White rabbits. Egyptian Journal of Animal Production, 51(3):210-215.

Lewczuk A., Postek, A., Brzozowska, W., Michalik, D., Janiszewska, M. 2001. The value of chosen pre- and post-slaughter traits for the estimation of lean yield in valuable carcass parts of Danish White rabbit. Anim. Sci. Pap. Rep., 19, 141-155. 
Lukefahr S.D., Ozimba C.E. 1991. Prediction of carcass merit from live body measurements in rabbits of four breed-type. Livestock Production Science, 29: 323-334.

Michalik, D., Lewczuk, A., Wilkiewicz-Wawro, E., Brzozowski, W. 2006. Prediction of the meat content of the carcass and valuable carcass parts in French lop rabbits using some traits measured in vivo and post mortem. Czech Journal of Animal Science, 51 (9): 406-415.

Ogah D. M. 2011. Assessing size and conformation of the body of Nigerian indigenous turkey. Slovak Journal of Animal Science, 44 (1): 21-27.

Oliveira M. C., Moura C. D., Arantes U. M., Faria E. B., Lui J. F., Caires D. R. 2004. Body measurements and its coefficient of correlation with the performance index of sexed rabbits slaughtered at different ages. Proceedings of the 8th World Rabbit Congress, 710 September. Puebla, Mexico. pp. 110-113.

Pinna W., Marongiu M. L., Sedda P., Moniello G., Nizza A., Piccolo G. 2004. Linear measurements of carcass as a tool to improve the evaluation of the rabbit meat production. In Proc. 8th World Rabbit Congress, 7-10 September. Puebla, Mexico. pp. 1447-1451.

Shahin K. A. 2001. Sources of shared variability of muscle, fat and bone weight distribution in New Zealand White rabbits. Animal Research, 50: 165-179.

Shahin K. A., Hassan N.S. 2000. Sources of shared variability among body shape characters at marketing age in New Zealand White and Egyptian rabbit breeds. Annales de Zootechnie, 49: 435-445.

Shemeis A.R., Abdallah, O. Y. 2000. Possibilities of developing favourable body fat partition via selection indexes- application on rabbits. Archiv Tierzucht Dummerstorf, 43: 193-201.

Shemeis, A.R. 1999. Selection indexes for improving carcass meatinessindicating traits in New Zealand White rabbits. Alex. Journal of Agriculture Research, 44 (3): 41-53.

SPSS. 2007. Statistical Package for the Social Sciences. SPSS Inc., Chicago, SPSS Inc., 444 Michigan Avenue, IL60611.

Udeh I. 2013. Prediction of body weight in rabbits using principal component factor scores in multiple linear regression model. Rabbit Genetics, 3 (1): 1-6. 


\section{التتبؤ بوزن العضلات الكلي من الصفات المظهرية فى الأرانب باستخدام تحليل المكونات الأساسية}

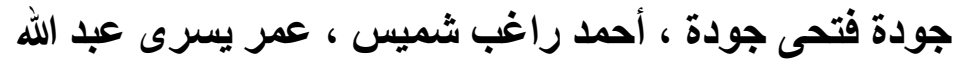

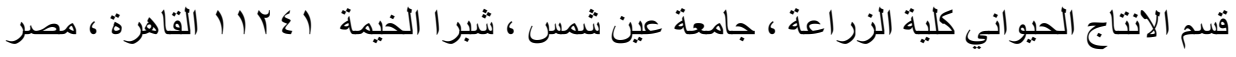

تم استخدم عدد ^اب أرنب نيوزيلندى أبيض للتنبؤ بوزن العضلات الكلى (TMW)

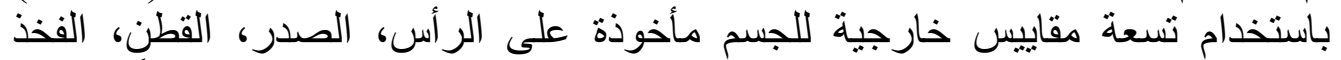

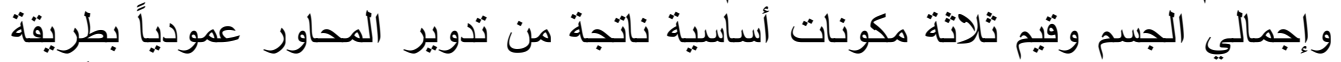

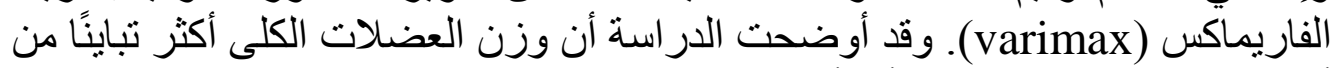

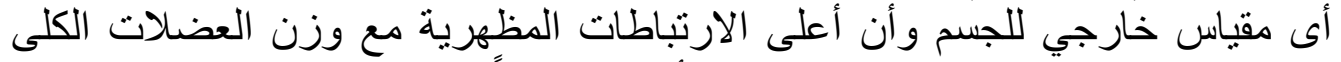

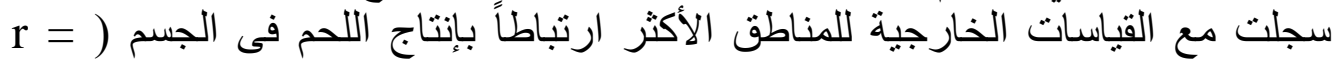

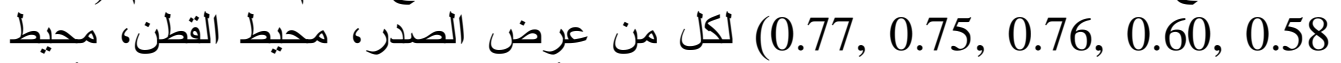

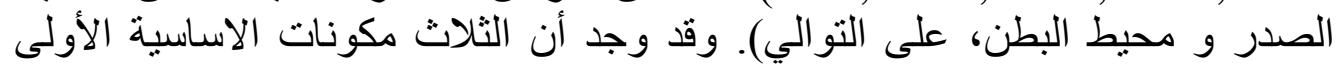

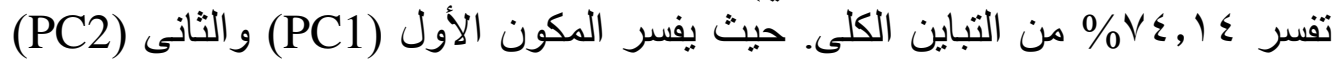

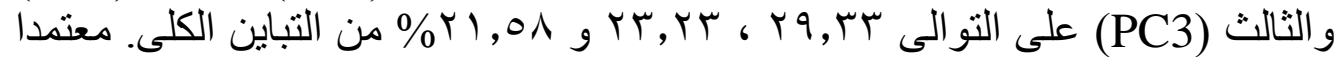

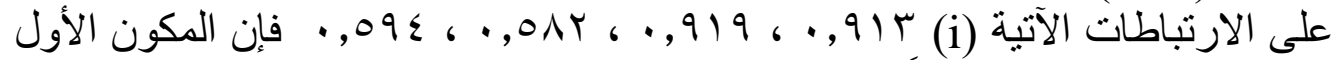

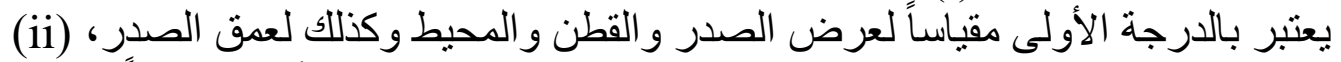

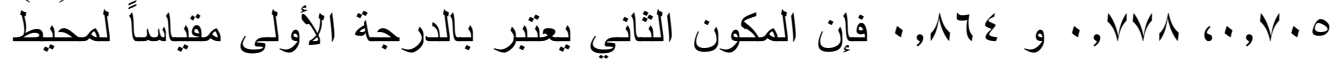

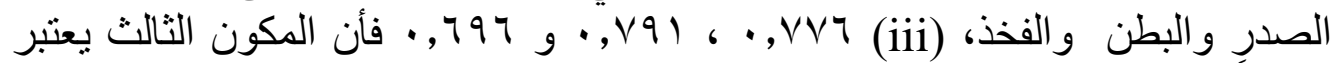

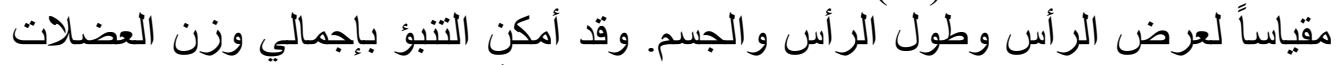

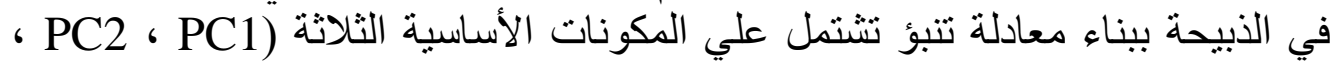

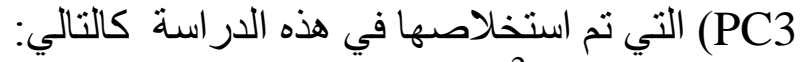

$\mathrm{TMW}=728.3$ + 100.8 PC1+ 59.3 PC2 $\quad\left(\mathrm{R}^{2}=69 \%\right)$, $\mathrm{TMW}=728.3$ + 100.8 PC1+ 59.3 PC2 + 48.2 PC3 $\left(\mathrm{R}^{2}=80 \%\right)$. التوصية: نطبيق تحليل المكونات الاساسية كان مفيدا فى استبعاد الارتباطات الخطية

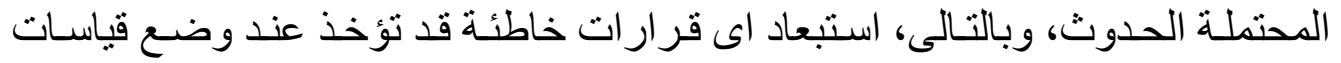
الجسم الخارجية مع بعضها البعض في الانحدار المتعدد. 